\title{
Beyond aerodigestion: exaptation of feeding-related mouth movements for social communication in human and non- human primates
}

Article

Accepted Version

Murray, L., Scalfani, V., Rayson, H., De Pascalis, L., Bozicevic, L. and Ferrari, P. F. (2017) Beyond aerodigestion: exaptation of feeding-related mouth movements for social communication in human and non-human primates. Behavioral and Brain Sciences, 40. e397. ISSN 0140-525X doi: https://doi.org/10.1017/S0140525X16001941 Available at https://centaur.reading.ac.uk/67552/

It is advisable to refer to the publisher's version if you intend to cite from the work. See Guidance on citing.

To link to this article DOI: http://dx.doi.org/10.1017/S0140525X16001941

Publisher: Cambridge University Press

All outputs in CentAUR are protected by Intellectual Property Rights law, including copyright law. Copyright and IPR is retained by the creators or other copyright holders. Terms and conditions for use of this material are defined in the End User Agreement. 


\section{www.reading.ac.uk/centaur}

\section{CentAUR}

Central Archive at the University of Reading

Reading's research outputs online 
<COMP: BRITISH SPELLING AND USAGE OK>

$<\mathrm{CT}>$ Beyond aerodigestion: Exaptation of feeding-related mouth movements for social communication in human and non-human primates

$<$ CA $>$ Lynne Murray, ${ }^{\text {a,b }}$ Valentina Sclafani, ${ }^{a}$ Holly Rayson, ${ }^{a}$ Leonardo De Pascalis, ${ }^{\mathrm{c}}$ Laura Bozicevic, ${ }^{a}$ and Pier Francesco Ferrarid,e

$<$ CAA $>$ a School of Psychology and Clinical Language Sciences, University of Reading, Harry Pitt Building, Earley Gate, Reading, RG6 7BE; 'b Stellenbosch University, South Africa; University of Cape Town, South Africa; ${ }^{\mathrm{C}}$ Institute of Psychology Health and Society, Eleanor Rathbone Building, University of Liverpool, Liverpool, United Kingdom, L69 7ZA; ' Dipartimento di Neuroscienze, Università di Parma, Unità di Fisiologia, 43125 Parma, Italy; ' Institut des Sciences Cognitives Marc Jeannerod, CNRS, Bron, France.

lynne.murray@reading.ac.uk

v.sclafani@reading.ac.uk

h.rayson@pgr.reading.ac.uk

leonardo.depascalis@liverpool.ac.uk

I.bozicevic@reading.ac.uk

pierfrancesco.ferrari@unipr.it 


\author{
https://www.reading.ac.uk/psychology/about/staff/lynne-murray.aspx \\ https://www.researchgate.net/profile/Valentina_Sclafani \\ https://www.researchgate.net/profile/Holly_Rayson \\ https://www.liverpool.ac.uk/psychology-health-and-society/staff/leonardo- \\ de-pascalis/ \\ https://www.researchgate.net/profile/Laura_Bozicevic \\ http://en.unipr.it/ugov/person/17750
}

$\langle\mathrm{C}-\mathrm{AB}\rangle$

\begin{abstract}
Three arguments are advanced from human and non-human primate infancy research for the exaptation of ingestive mouth movements (tongue-protrusion and lipsmacking) for the purposes of social communication: Their relation to affiliative behaviours; their sensitivity to social context; and their role in social development. Although these behaviours may have an aerodigestive function, such an account of their occurrence is only partial.
\end{abstract}

\title{
$<$ C-Text begins $>$
}

Keven \& Akins (K\&A) view infant mouth movements such as tongue protrusion (TP), as part of the system for regulating ingestion in relation to breathing. They view these behaviors as stereotyped, not goal-oriented, and unresponsive to stimulation, albeit 
varying with arousal. In contrast, we present three arguments from research on early parent-infant relationships, including cross-species and clinical samples, for the social function of such mouth movements: their relation to affiliative behaviors; their sensitivity to social context; and their role in social development.

\section{$<\mathrm{CB}>1$. Relationship between aerodigestive and affiliative behaviours.}

Observational studies of human and non-human primate (NHP) infants are remarkably consistent in showing that mouth movements originating in ingestion nevertheless have distinct, communicative, significance (Trevarthen 1979; Van Hooff 1962). These include TP in humans and lip-smacking (LS) in NHPs, including rhesus macaques. In each case, the behaviour rapidly becomes prominent in early parent-infant interactions (Ferrari et al. 2009; Trevarthen 1974; Murray et al. in press), and is highly organized, systematically co-occurring with other, clearly affiliative, behaviors. For instance, in humans, TP in the first two months is associated with smiling, wide mouth-opening and positive vocalizations, a cluster of expressions termed "prespeech" (Figure 1; Murray et al. in press); these expressions occur during direct gaze to the adult's face, often accompanied by arm waving with open hand movements (Fig. 1a) (Lavelli \& Fogel 2002; 2005; 2013, SI1; Trevarthen 1974; 1979).

\section{[COMP: INSERT FIGURE 1 (Sloman) with Fig. 1 Caption HERE]}

In macaques, LS similarly appears as part of social encounters, and co-occurs with direct gaze and proximal contact with the parent; even newborns actively solicit 
their mothers to interact using LS (Dettmer et al. 2016; Ferrari et al. 2009). The time course of TP and LS is strikingly similar in humans and monkeys, increasing in frequency over the first few weeks, and then declining with the reduction in face-to-face interactions and the infant's growing exploration (Ferrari et al. 2009; Trevarthen \& Aitken 2001). Notably, each behavior is functionally autonomous with respect to digestive chewing- whether in terms of its co-occurrence (TP [Murray et al. in press]; [SI1]), or developmental trajectory (LS [Ghazanfar \& Takahashi 2014]).

$<\mathrm{CB}>2$. Sensitivity to social context. Infant TP and LS are highly sensitive and responsive to others' interactive behavior. In addition to the consistent evidence from well-conducted studies for neonatal imitation of these gestures (Simpson et al. 2014), human research using experimental perturbations shows that if normal face-to-face contact is broken by the parent adopting a still, blank, face, infants show less positive social engagement (Mesman et al. 2009), including reduced TP (Murray \& Trevarthen 1985). This effect is not simply a function of lack of parental stimulation lowering infant arousal, since similar reductions in engagement (and TP) occur when infants see their parent in a non-contingent versus identical contingent face-to-face interaction (Murray \& Trevarthen 1985; Nadel et al. 1999). Disturbances in clinical populations also demonstrate the influence of variations in face-to-face interactions on human infants' social responses. For example, two-month-olds of socially anxious mothers show low levels of social engagement themselves, including TP, an effect that is mediated by their mothers' reduced positive social signals (Murray et al. 2007). Similar effects are found for infants of depressed mothers (Murray et al. 1996). Parallel findings to the human 
experimental studies emerge from NHP research: specifically, infant macaques reduce their LS and social attention when presented with a still face versus an active interactive experimenter; and they show more LS and attention when an experimenter interacts with them using contingent, imitative, mouth responses rather than similarly prominent, but non-contingent, repetitive mouth movements, despite the latter condition providing more overall stimulation (Sclafani et al. 2014).

\section{$<\mathrm{CB}>$ 3. Role of infant TP and LS in later social development. Human}

observational studies show that parents respond positively to early infant signs of social engagement or "prespeech," imitating and affirming them, and according them communicative and playful significance (Lavelli \& Fogel 2002; Trevarthen 1979; Murray et al. in press; SI2). In turn, the further development of these infant behaviours is promoted by parental facial responsiveness (Murray et al. in press), so that cultural differences in its prevalence (e.g., as between US/European and some African populations) predict somewhat different infant social trajectories (Kärtner et al. 2010; Wormann et al. 2012). Face-to-face interactions between mother and infant macaques also influence the development of infant social functioning: Monkey neonates that receive more facial responsiveness from their mothers spend more time in social contact with other monkeys at 2 months of age, and they initiate more social interactions at 5 months (Dettmer et al. 2016). That this effect is driven by experience of face-to-face interactions, rather than physical contact, is indicated by the finding that nursery-reared infants receiving mutual gaze and LS from a human caregiver subsequently show more social interest and social contact with peers than infants receiving either handling without 
gaze and LS, or standard nursery care. Notably, infant experience of early social interactions influences putative mirror neuron system responses, with infant monkeys raised with their biological mothers already demonstrating more mu desynchronization during observation of LS at three days postpartum compared to those raised apart (Vanderwert et al. 2015). Such impact suggests a preparedness of the neonate brain to respond to social cues by harnessing aerodigestive behaviours, with a rudimentary mirror system rapidly refined by early experience. This may increase neural sensitivity to socially relevant stimuli such as LS, and thereby confer significant benefits for infants' navigation of the complex social world into which they are born (Vanderwert et al. 2015). Recent research with human children similarly suggests mirror system involvement in the processing of facial expressions from a young age (Rayson et al. 2016).

In sum, we provide evidence from naturalistic, experimental and clinical studies to show that infant mouth movements like TP/LS are complex and sensitive to context, and are fundamentally embedded in social interactions early in development, with longerterm significance for social functioning. Therefore, while both TP/LS may indeed have aerodigestive origins, they have also been exapted for uniquely social purposes. $<$ C-Text ends $>$

$<$ RFT $>$ References[Lynne Murray, Valentina Sclafani, Holly Rayson, Leonardo De Pascalis, Laura Bozicevic, and Pier Francesco Ferrari ][LM]

$<$ refs $>$ 
Dettmer, A. M., Kaburu, S. S .K., Simpson, E. A., Paukner, A., Sclafani, V, Byers, K. L., Murphy, A. M., Miller, M., Marquez, N., Miller, G. M., Suomi, S. J. \& Ferrari, P. F. (2016) Neonatal face-to-face interactions promote later social behaviour in infant rhesus monkeys. Nature Communications 7:11940. [LM]

Ferrari, P. F, Paukner, A., Ionica, C. \& Suomi, S. (2009) Reciprocal face-to-face communication between rhesus macaque mothers and their newborn infants. Current Biology 19:1768-72. [LM]

Ghazanfar, A. A. Takahashi, D. Y. (2014) The evolution of speech: Vision, rhythm, cooperation. Trends in Cognitive Neuroscience 18(10):543-53. [LM]

Kärtner , J., Keller, H. \& Yovsi, R. D. (2010) Mother-infant interaction during the first 3 months: The emergence of culture-specific contingency patterns. Child Development 81(2):540-54. [LM]

Lavelli, M. \& Fogel A. (2002) Developmental changes in mother-infant face-to-face communication: Birth to 3 months. Developmental Psychology 38:288-305. [LM]

Lavelli M. \& Fogel A. (2005) Developmental changes in the relationship between the infant's attention and emotion during early face-to-face communication: The 2month transition. Developmental Psychology 41:265-80. [LM]

Lavelli, M. \& Fogel A. (2013) Interdyad differences in early mother-infant face-to-face communication: Real-time dynamics and developmental pathways.

Developmental Psychology 49:2257-71. [LM] 
Mesman, J., van IJzendoorn, M. H., Bakermans-Kranenburg, M. J. (2009) The many faces of the Still-Face Paradigm: A review and meta-analysis. Developmental Review 29:120-62. [LM]

Murray, L., Cooper, P. J., Creswell, C., Schofield, E. \& Sack, C. (2007) The effects of maternal social phobia on mother-infant interactions and infant social responsiveness. Journal of Child Psychology and Psychiatry 48:45-52. [LM]

Murray, L., De Pascalis, L., Bozicevic, L., Hawkins, L., Sclafani, V., Ferrari, P. F. The functional architecture of mother-infant communication, and the development of infant social expressiveness in the first two months. Scientific Reports (in press).

Murray, L., Fiori-Cowley, A., Hooper, R. \& Cooper, P. J. (1996) The impact of postnatal depression and associated adversity on early mother-infant interactions and later infant outcome. Child Development 67:2512-26. [LM]

Murray, L. \& Trevarthen, C. (1985) Emotional regulation of interactions between two month olds and their mothers. In: Social perception in infants, ed. T. M. Field \& N. Fox. Ablex. [LM]

Nadel, J., Carchon, I., Kervella, C., Marcelli, D. \& Reserbat-Plantey, D. (1999) Expectancies for social contingency in 2 month-olds. Developmental Science 2:164-73. [LM]

Rayson, H., Bonaiuto, J., Ferrari, P. \& Murray, L. (2016) Mu Desynchronization during observation and execution of facial expressions in 30-month-old children. Developmental Cognitive Neuroscience 19:279-87. [LM] 
Sclafani, V., Paukner, A., Suomi, S. \& Ferrari, P. F. (2014) Imitation promotes affiliation in infant macaques at risk for impaired social behaviors. Developmental Science pp. 1-8. [LM]

Simpson, E., Murray, L., Paukner, A. \& Ferrari, P. (2014) The mirror neuron system as revealed through neonatal imitation: Presence from birth, predictive power, and evidence of plasticity. Philosophical Transactions of the Royal Society Biological Sciences 369:20130289. [LM]

Trevarthen, C. (1974) Conversations with a two-month-old. New Scientist 62(896):23035. $[\mathrm{LM}]$

Trevarthen, C. (1979) Communication and cooperation in early infancy: A description of primary intersubjectivity. In: Before speech: The beginning of interpersonal communication, ed. M. Bullowa, pp. 321-47. Cambridge University Press. [LM]

Trevarthen, C. \& Aitken, A. (2001) Infant intersubjectivity: Research, theory, and clinical applications. Journal of Child Psychology and Psychiatry 42(1):3-48. [LM]

Vanderwert, R. E., Simpson, E. A., Paukner, A., Suomi, S., Fox, N. \& Ferrari, P. F. (2015) Early social experience affects neural activity to affiliative facial gestures in newborn nonhuman primates. Developmental Neuroscience 37:243-52. Available at: http://dx.doi.org/10.1159/000381538 [LM]

Van Hooff, J. A. R. A. M. (1962) Facial expressions of higher primates. Symposium of the Zoological Society of London 8:97-125. [LM]

Wormann, V., Holodynski, M., Kartner, J. \& Keller, H. (2012) A cross-cultural comparison of the development of the social smile. A longitudinal study of 
maternal and infant imitation in 6- and 12-week-old infants. Infant Behavior and Development 35:335-47. [LM]

Supplementary Information for Lynne Murray et al. commentary on Keven and Akins

\section{Structure of infant behavior}

We coded infant behaviors ('Non-Communicative' Mouth Movements (e.g., chewing), Tongue Protrusions, Mouth Openings, Smiles, Cooing Vocalizations, Biological Events (e.g., sneezes, hiccoughs), Negative Mouth Movements (e.g., pouts), Negative Expressions (e.g., frowns), and Negative Vocalizations (e.g., cry, fret)), as discrete events, on a one-second basis, during naturalistic mother-infant face-to-face interactions, from video-recordings of 20 dyads, between 1 and 9 weeks of life. Infant events were then investigated through Principal Components Analysis (PCA), using Parallel Analysis, to determine the number of components to extract, and Simplimax rotation. Three components emerged (only behaviors with absolute value loadings $>.5$ are reported), explaining $61.01 \%$ of the variance $\left(\mathrm{KMO}=0.673\right.$; Bartlett's Test of Sphericity $\mathrm{X}^{2}\left({ }^{2}\right)=$ 194.401, P < 0.001): the first one, infant social expressiveness, included Mouth Openings (.781), Smiles (0.753), Tongue Protrusions (0.712), and Cooing vocalizations (0.689), all positively loaded, and, with negative loading, "Non-Communicative" Mouth Movements (- 0.561). Behaviors in the second component were Negative Mouth Movements (0.529), Negative Expressions (0.708), and Negative Vocalizations (0.803), that is, infant negative affect; while the third component was Biological Events (0.873). 
2. Maternal comments following infant Tongue Protrusion

Using the video-recordings described above, we coded all maternal verbal comments following infant Tongue Protrusions. All but one infant made some tongue protrusion during face-to-face interaction: $52.63 \%$ of mothers directly responded to their infant's tongue protrusions with verbal comments (the others responded only with facial movements, such as imitations). Of their verbal comments, none was related to feeding or to an interpretation of their infant's tongue protrusions as indicating hunger. Twenty-five percent showed a social interpretation ("What are you trying to say?", "Are you telling me that you had a lovely day?"); $58.33 \%$ showed a playful interpretation (“Oooh! I saw your tongue! There it is! Is it hiding!"), while $16.67 \%$ of comments were used to simply acknowledge the behavior ("Sticking your tongue out"). A Chi Square test of Goodness of Fit was used to test whether the mothers' comments were equally distributed among these four categories (attributing tongue protrusion to their infant being hungry, social, playful, or whether the comments were simply used to acknowledge the infant's behavior). The distribution of frequencies was found to differ significantly from what would be expected in the case of a truly independent distribution $\left(\mathrm{X}^{2}(3)=17.333\right.$, $\mathrm{p}<0.001$ ), with standardized residuals showing that the kinds of comment showing the greatest discrepancies were hunger interpretations (Standardised Residual $=-2.828$ ) being the least represented, and playfulness interpretation (Standardised Residual=3.771) being the most frequent. 

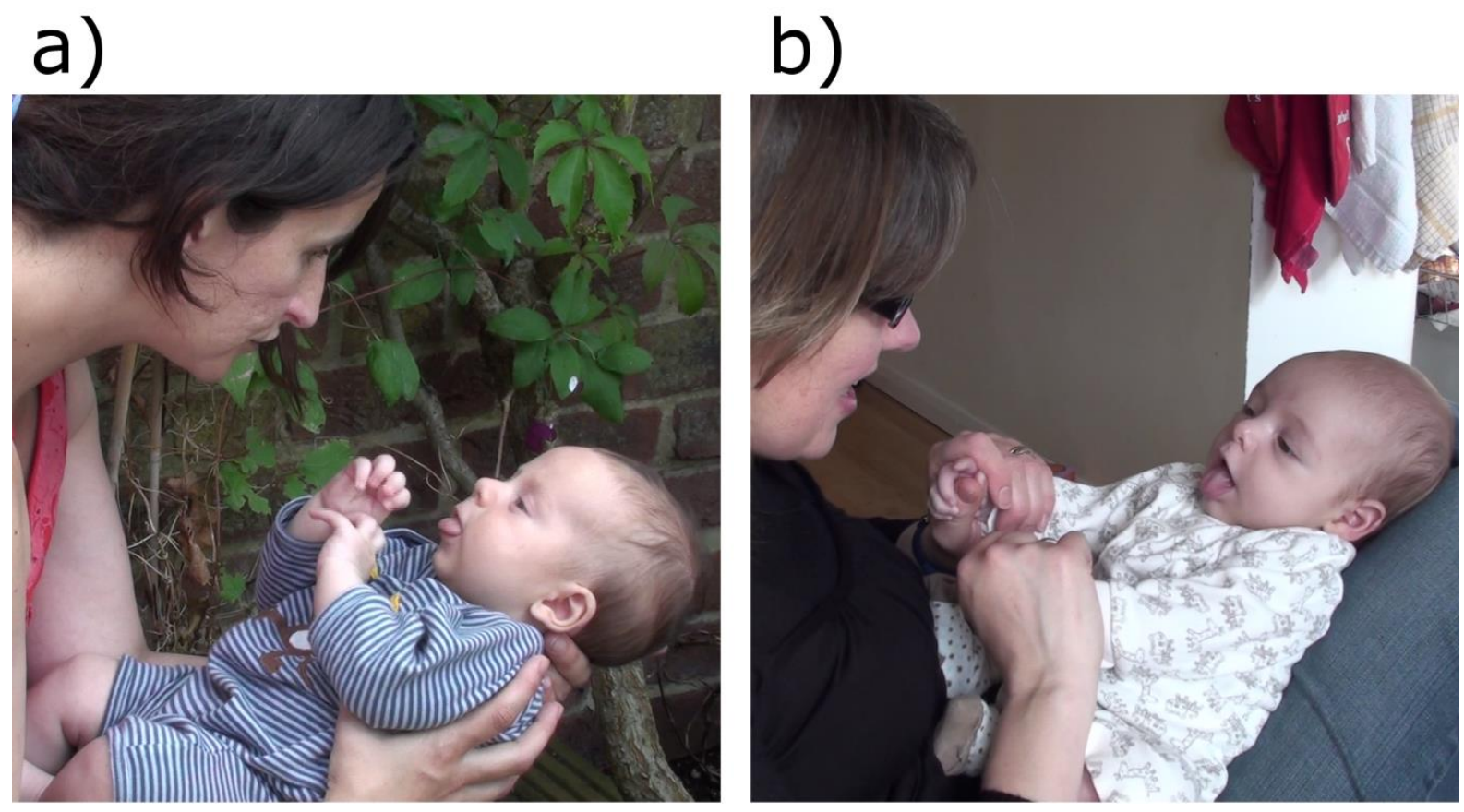

Figure 1a and b: Infant TP, with and without arm/hand movements, during face-to-face interaction 
